\title{
Research on Assessment Index System for Low-carbon Development
}

\author{
Chengzhi Niu ${ }^{1}$, Yougan $\mathrm{Zhu}^{1, *}$ \\ ${ }^{1}$ Beijing Institute of Fashion Technology, Chaoyang District, Beijing, 100020, PRC
}

\begin{abstract}
Due to the severe situation of global climate change and depletion of energy resources, lowcarbon development has become an inevitable choice for global climate change and maintaining sustainable economic and social development. In order to promote low-carbon development, we should scientifically evaluate the low-carbon development status of a country, economy or region. At present, the research on low-carbon evaluation indicators is still in the exploratory stage. There are not many low-carbon indicators that are really used in practice, and there is currently no recognized and authoritative low-carbon evaluation indicator system. Based on this, this article attempts to use the analytic hierarchy process to further study the low-carbon development indicator system, to establish a scientific and objective system of low-carbon development indicators, and use such an indicator system to guide and promote low-carbon development.
\end{abstract}

\section{Introduction}

Low-carbon development refers to a social development model based on clean and efficient use of energy and low-emissions as the basic economic feature. [1] Lowcarbon development is a sustainable development path with low-carbonization as the main feature. [2]

Low-carbon development is a new trend in global economic and social development. To achieve lowcarbon development, we should determine a low-carbon development strategy, improve a low-carbon legal framework, strengthen the construction of low-carbon systems, promote a low-carbon industrial structure, implement low-carbon preferential policies, use lowcarbon market mechanisms, and increase low-carbon financial input Develop a low-carbon circular economy, rely on low-carbon technological innovation and form a low-carbon lifestyle.

In order to cope with global warming, countries must effectively transform their economic growth patterns, optimize and adjust economic and industrial structures, promote the diversified development of energy, accelerate the replacement of conventional fossil energy by renewable energy and new energy, establish lowcarbon consumption patterns, and promote Energy conservation, emission reduction, improvement of energy utilization efficiency, advancement of scientific and technological progress, and support for the establishment of a new high-efficiency, clean, and lowcarbon energy industrial system. From the perspective of low-carbon development, low-carbon development can be described as a global change involving production methods, lifestyles and values, because it requires human beings to abandon the social production methods that relied on high-carbon in the past and turn to green development.

\section{Construction of Assessment Index System for Low-carbon Development}

The low-carbon evaluation index systems proposed by different scholars from different angles are different from each other due to different considerations. [3] However, these studies have laid the foundation for the low-carbon evaluation indicators and have important theoretical and practical value. It can be seen from the figure that the current research enthusiasm of the lowcarbon development indicator system by Chinese scholars continues to rise, and experts and scholars are trying to establish a scientific indicator system that can objectively evaluate low-carbon development.

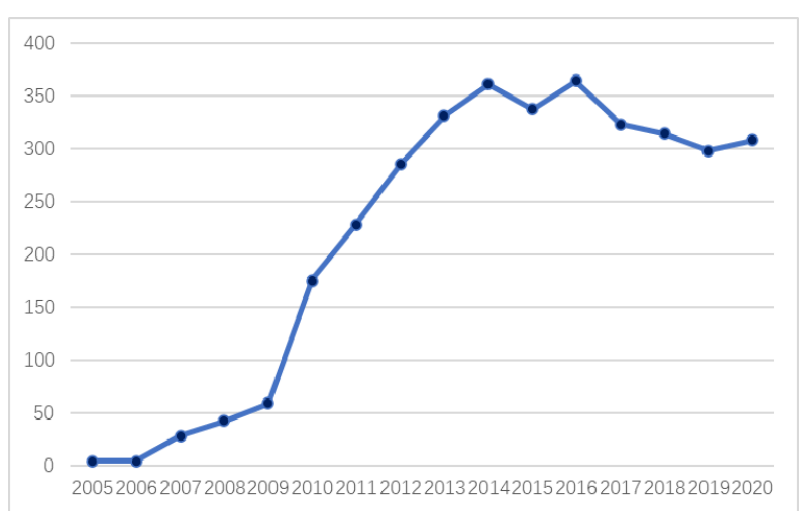

Fig. 1. Number of papers published of Low-carbon development Index in China

\footnotetext{
* Corresponding author: macrov@yeah.net
} 
Low-carbon development is a development model that aims to achieve sustainable economic and social development, promote efficient use of energy, promote regional clean development, promote low-carbon product development, and maintain global ecological balance. Low-carbon development can be defined as a new type of development that links the environment, energy, and economy.[4] The purpose of low-carbon development is to achieve social and economic development and protection of the ecological environment, while mitigating climate change and promoting the sustainable development of mankind.[5] Based on the comprehensive analysis of previous scholars' relevant research results, this article starts with the meaning of low-carbon and the construction of lowcarbon evaluation index system, and analyses the key aspects in the process of establishing and applying lowcarbon evaluation index system. This article finally establishes an evaluation index system that can scientifically measure the level of low-carbon development.

\subsection{Principles of Low-Carbon Development Index Construction}

This article follows the following principles in constructing a low-carbon development evaluation index system:

\subsubsection{Systematic and hierarchical principle}

The evaluation index system must be based on certain logical rules and present a hierarchy of structure. The low-carbon evaluation index system must be able to comprehensively reflect all aspects of low-carbon development, and have the characteristics of wide coverage and strong system. The evaluation index system is a complex system. [6] It includes several subsystems. Different indicators should be used at different levels. The levels should be separated according to the structure of the system and the indicators should be classified. The indicator system has a clear structure and is easy to use. It is also necessary to avoid overlap between indicators.

\subsubsection{Principle of Comparability}

This article tries to use common names, concepts and calculation methods to set up evaluation indicators to make relevant evaluation indicators comparable. The index system should take into account the issue of comparability between regions and time at the same time, in order to carry out horizontal and vertical analysis and comparison. The indicators at the same indicator level should be relevant and comparable.

\subsubsection{The principle of combining qualitative analysis and quantitative analysis}

It is reasonable for the evaluation index system to be measurable. The qualitative indicators must be quantified. Of course, some indicators are difficult to quantify. They can be divided into several levels to quantify the qualitative indicators. The evaluation index system should be a combination of quantitative and qualitative. The low-carbon evaluation index system should be quantified as much as possible. For some indicators that are difficult to quantify, but their impact is significant, qualitative indicators can also be used to describe. Qualitative indicators should have certain quantitative means corresponding to them, such as using expert questionnaire surveys to determine some indicators that are difficult to quantify. However, due to the difficulties and arbitrariness of expert survey and other methods, when designing the evaluation index system, the number of difficult to quantify indexes should be minimized. In addition, the calculation method of the index should be clear and not too complicated, and the data required for the calculation should be easy to obtain and reliable.

\subsubsection{The principle of combining static and dynamic indicators}

The evaluation index system must have both static indicators that reflect the level of development and dynamic indicators that can comprehensively reflect the dynamic changes in the low-carbon development process. An absolutely unchanged indicator system is unreliable, and the indicator system will change over time. Lowcarbon development is a gradual process, so the design of the evaluation index system should fully consider the dynamic changes of the system. It should be able to comprehensively reflect the development process to predict and manage the process of low-carbon development. At the same time, within a certain period of time, the content of the index system should be relatively stable.

\subsection{Construction Assessment Index System for Low-carbon Development}

The indicators in the indicator system must have a clear purpose and accurate definition. If the meaning of the selected basic indicators is unclear, then their calculation formulas or calculation methods are difficult to be unified. In addition, the setting of indicators should be easy to understand, and the difficulty and reliability of data acquisition should be considered.

According to the basic principles of low-carbon evaluation index system design, the evaluation system should be composed of several levels. Researchers generally adopt a three-level structure of target level, criterion level and index level. The target level is the overall goal of the design of the evaluation index system for low-carbon development. The criterion level is a subtarget established under the target level, and it is a concrete reflection of the target level. The indicator layer is a further subdivision of the criterion layer and is a set of basic indicators. Most scholars use the three-level system architecture of target level, criterion level and 
index level to establish the index system, but their specific connotations are quite different.

The system-level structure using three levels of target level, criterion level and indicator level is a relatively common low-carbon indicator structure system. The index system constructed is shown in Table 1. This system has a clear hierarchy and is easy to understand and apply.

\section{Calculation of index weights based on the Analytic Hierarchy Process}

The analytic hierarchy process is a decision-making method that decomposes the elements that are always relevant to decision-making into goals, criteria, indicators and other levels, and then conducts qualitative and quantitative analysis on this basis. The analytic hierarchy process has certain steps. The first step is to establish a hierarchical structure model. The second step is to construct a contrast matrix to calculate the weight vector and do the consistency test. Finally, it is to calculate the combined weight vector and do the combined consistency test. The analytic hierarchy process well reflects the hierarchical and systematic nature of the comprehensive evaluation process.

Table 1. The hierarchical model of Index System for Lowcarbon Development

\begin{tabular}{|c|c|c|}
\hline Target layer & Criterion layer & Indicator layer \\
\hline \multirow{16}{*}{$\begin{array}{c}\text { Index } \\
\text { System for } \\
\text { Low-carbon } \\
\text { Development } \\
\text { A }\end{array}$} & \multirow{4}{*}{$\begin{array}{c}\text { Technical } \\
\text { innovation } \\
\text { indicators B1 }\end{array}$} & $\begin{array}{l}\text { Low-carbon technology } \\
\text { investment amount } \mathrm{C} 1\end{array}$ \\
\hline & & $\begin{array}{c}\text { Low-carbon material } \\
\text { utilization } \mathrm{C} 2\end{array}$ \\
\hline & & $\begin{array}{l}\text { Low-carbon technology } \\
\text { R\&D investment ratio C3 }\end{array}$ \\
\hline & & $\begin{array}{c}\text { Low-carbon knowledge } \\
\text { penetration rate } \mathrm{C} 4\end{array}$ \\
\hline & \multirow{4}{*}{$\begin{array}{c}\text { Energy } \\
\text { management } \\
\text { indicators B2 }\end{array}$} & $\begin{array}{l}\text { Proportion of non-fossil } \\
\text { energy C5 }\end{array}$ \\
\hline & & Energy recycling rate C6 \\
\hline & & $\begin{array}{l}\text { Emissions per unit of } \\
\text { energy consumption } \mathrm{C} 7\end{array}$ \\
\hline & & $\begin{array}{l}\text { Number of professional } \\
\text { management talents C8 }\end{array}$ \\
\hline & \multirow{4}{*}{$\begin{array}{l}\text { Low-carbon } \\
\text { consumption } \\
\text { indicators B3 }\end{array}$} & $\begin{array}{l}\text { Average production carbon } \\
\text { emissions C9 }\end{array}$ \\
\hline & & $\begin{array}{l}\text { Carbon emissions per capita } \\
\text { C10 }\end{array}$ \\
\hline & & $\begin{array}{c}\text { Percentage of green travel } \\
\text { residents } \mathrm{C} 11\end{array}$ \\
\hline & & $\begin{array}{l}\text { Low-carbon awareness } \\
\text { recognition } \mathrm{C} 12\end{array}$ \\
\hline & \multirow{4}{*}{$\begin{array}{c}\text { Economic } \\
\text { structure } \\
\text { indicators B4 }\end{array}$} & $\begin{array}{l}\text { Proportion of tertiary } \\
\text { industry C13 }\end{array}$ \\
\hline & & $\begin{array}{l}\text { Low-carbon transformation } \\
\text { rate of traditional industries } \\
\text { C14 }\end{array}$ \\
\hline & & $\begin{array}{l}\text { Carbon emissions per unit } \\
\text { of GDP C15 }\end{array}$ \\
\hline & & $\begin{array}{l}\text { Energy-saving standard } \\
\text { implementation rate } \mathrm{C} 16\end{array}$ \\
\hline
\end{tabular}

We have invited many experts to revise the indicator system and give scores.

The judgement matrix was constructed by using the Delphi Method. The Delphi method will investigate the opinions of experts on the questions raised in the questionnaire in multiple rounds. This method is reliable in the research field.

Before analysing the indicators of Analytic Hierarchy Process, we need to check their consistency first.

We use the consistency index $\mathrm{CI}$ and the ratio $\mathrm{CR}$ to check the consistency. When $\mathrm{CR}<0.1$, it indicates that the judgment matrix has passed the consistency test; otherwise, the judgment matrix should be corrected.

The calculation process of the consistency index is as follows:

Table 2. The A-B Judgment Matrix

\begin{tabular}{|c|c|c|c|c|}
\hline $\mathrm{A}$ & $\mathrm{B} 1$ & $\mathrm{~B} 2$ & $\mathrm{~B} 3$ & $\mathrm{~B} 4$ \\
\hline $\mathrm{B} 1$ & 1 & 5 & 4 & 2 \\
\hline $\mathrm{B} 2$ & $1 / 5$ & 1 & $1 / 3$ & $1 / 3$ \\
\hline $\mathrm{B} 3$ & $1 / 4$ & 3 & 1 & $1 / 3$ \\
\hline $\mathrm{B} 4$ & $1 / 2$ & 3 & 3 & 1 \\
\hline
\end{tabular}

Table 3. The B2-C Judgment Matrix

\begin{tabular}{|c|c|c|c|c|}
\hline $\mathrm{B} 1$ & $\mathrm{C} 1$ & $\mathrm{C} 2$ & $\mathrm{C} 3$ & $\mathrm{C} 4$ \\
\hline $\mathrm{C} 1$ & 1 & $1 / 3$ & 4 & 1 \\
\hline $\mathrm{C} 2$ & 3 & 1 & 5 & 2 \\
\hline $\mathrm{C} 3$ & $1 / 4$ & $1 / 5$ & 1 & $1 / 3$ \\
\hline $\mathrm{C} 4$ & 1 & $1 / 2$ & 3 & 1 \\
\hline
\end{tabular}

Table 4. The B2-C Judgment Matrix

\begin{tabular}{|c|c|c|c|c|}
\hline B2 & C5 & C6 & C7 & C8 \\
\hline C5 & 1 & 2 & 4 & $1 / 2$ \\
\hline C6 & $1 / 2$ & 1 & 3 & $1 / 4$ \\
\hline C7 & $1 / 4$ & $1 / 3$ & 1 & $1 / 4$ \\
\hline C8 & 2 & 4 & 4 & 1 \\
\hline
\end{tabular}

Table 5. The B3-C Judgment Matrix

\begin{tabular}{|c|c|c|c|c|}
\hline B3 & C9 & C10 & C11 & C12 \\
\hline C9 & 1 & 5 & 4 & $1 / 4$ \\
\hline C10 & $1 / 5$ & 1 & $1 / 2$ & $1 / 6$ \\
\hline $\mathrm{C} 11$ & $1 / 4$ & 2 & 1 & 4 \\
\hline $\mathrm{C} 12$ & $1 / 4$ & 6 & $1 / 4$ & 1 \\
\hline
\end{tabular}

Table 6. The B4-C Judgment Matrix

\begin{tabular}{|c|c|c|c|c|}
\hline B4 & C13 & C14 & C15 & C16 \\
\hline C13 & 1 & 4 & 2 & 3 \\
\hline $\mathrm{C} 14$ & $1 / 4$ & 1 & $1 / 3$ & 3 \\
\hline $\mathrm{C} 15$ & $1 / 2$ & 3 & 1 & 3 \\
\hline $\mathrm{C} 16$ & $1 / 3$ & $1 / 3$ & $1 / 3$ & 1 \\
\hline
\end{tabular}

The maximum eigenvalues $\lambda$ max obtained in the A-B judgment matrix is 4.1383, test coefficient is $\mathrm{CR}=\mathrm{CI} / \mathrm{RI}=0.0518<0.1$ we can see that the result has passed the test. The weight the matrix is $(0.4902,0.2891,0.1435,0.0772)^{\mathrm{T}}$. 
The maximum eigenvalues $\lambda$ max obtained in the B-C judgment matrixes are 4.0662, 4.2369, 4.1179, 4.0813, and the test coefficients CR are $0.0248,0.0887,0.0442$, 0.0304 . The four CR are less than 0.1 , we can see that all the judgment matrix passes the consistency test. The weight of the indicator layer is shown in Table 7.

Table 7. Low-carbon Development Index System Weight Table

\begin{tabular}{|c|c|c|}
\hline Criterion Layer & Indicator Layer & $\begin{array}{l}\text { Relative } \\
\text { Weight }\end{array}$ \\
\hline \multirow{4}{*}{$\begin{array}{c}\text { Technical } \\
\text { innovation } \\
\text { indicators } \\
49.02 \%\end{array}$} & $\begin{array}{l}\text { Low-carbon technology } \\
\text { investment amount }\end{array}$ & $23.63 \%$ \\
\hline & $\begin{array}{c}\text { Low-carbon material } \\
\text { utilization }\end{array}$ & $13.26 \%$ \\
\hline & $\begin{array}{l}\text { Low-carbon technology } \\
\text { R\&D investment ratio }\end{array}$ & $10.93 \%$ \\
\hline & $\begin{array}{l}\text { Low-carbon knowledge } \\
\text { penetration rate }\end{array}$ & $10.85 \%$ \\
\hline \multirow{4}{*}{$\begin{array}{c}\text { Energy } \\
\text { management } \\
\text { indicators } \\
28.91 \%\end{array}$} & $\begin{array}{c}\text { Proportion of non-fossil } \\
\text { energy }\end{array}$ & $8.81 \%$ \\
\hline & Energy recycling rate & $6.94 \%$ \\
\hline & $\begin{array}{l}\text { Emissions per unit of } \\
\text { energy consumption }\end{array}$ & $4.40 \%$ \\
\hline & $\begin{array}{c}\text { Number of professional } \\
\text { management talents }\end{array}$ & $4.14 \%$ \\
\hline \multirow{4}{*}{$\begin{array}{l}\text { Low-carbon } \\
\text { consumption } \\
\text { indicators } \\
14.35 \%\end{array}$} & $\begin{array}{c}\text { Average production carbon } \\
\text { emissions }\end{array}$ & $4.01 \%$ \\
\hline & $\begin{array}{c}\text { Carbon emissions per } \\
\text { capita }\end{array}$ & $3.61 \%$ \\
\hline & $\begin{array}{l}\text { Percentage of green travel } \\
\text { residents }\end{array}$ & $2.70 \%$ \\
\hline & $\begin{array}{l}\text { Low-carbon awareness } \\
\text { recognition }\end{array}$ & $2.28 \%$ \\
\hline \multirow{4}{*}{$\begin{array}{c}\text { Economic structure } \\
\text { indicators } \\
7.72 \%\end{array}$} & $\begin{array}{c}\text { Proportion of tertiary } \\
\text { industry }\end{array}$ & $2.05 \%$ \\
\hline & $\begin{array}{c}\text { Low-carbon } \\
\text { transformation rate of } \\
\text { traditional industries }\end{array}$ & $1.12 \%$ \\
\hline & $\begin{array}{c}\text { Carbon emissions per unit } \\
\text { of GDP }\end{array}$ & $0.79 \%$ \\
\hline & $\begin{array}{l}\text { Energy-saving standard } \\
\text { implementation rate }\end{array}$ & $0.48 \%$ \\
\hline
\end{tabular}

\section{Conclusion}

Through the low-carbon development indicator system established above, we put forward the following conclusions and recommendations:

The government should adjust the industrial structure to improve the level of industrial green development. The relevant departments should formulate market-based emission regulations to improve industrial green scale efficiency and increase environmental monitoring of medium-sized enterprises and introduce strict environmental protection measures. Environmental protection department should encourage the joint development of small and medium-sized enterprises, and strengthen the linkage between small and medium-sized enterprises and large enterprises in the upstream and downstream of the industrial chain. Related companies should establish a green networked supply chain, reduce the damage of medium-sized enterprises to the ecological environment, and achieve the goal of improving the level of industrial green development.

The government should promote technological innovation to improve the level of industrial green development. The authorities should upgrade traditional industries, strengthen technological transformation, and promote the development of a green circular economy. The relative departments should implement environmentally-friendly technologies and low-carbon industrial processes such as industrial energy-saving and water-saving, clean production, recycling, to improve green technology capabilities. Companies should promote the industrialization of green technologies and increase the enthusiasm of enterprises to develop green technologies and accelerate the construction of a green manufacturing system and promote the green development of the industry. The government should establish green manufacturing standards and formulate clean energy policies to restrict and guide the green development of industries. Companies should promote resource conservation and environmental protection through the advancement of low-carbon technology. It is necessary to develop alternative energy, especially renewable energy utilization technologies.

\section{Acknowledgement}

This research was financially supported by the nongovernment sponsored scientific research projects about Enhancement of the capabilities of China's Certified Public Valuer from the perspective of new standards of the Graduate School of Beijing Institute of Fashion Technology (Grand NO. HXKY05200310).

\section{References}

1. Common M. Measuring National Economics Performance without Using Prices[J]. Ecological Economics, 2007, 64: 92-102.

2. Ugur S, Ramazan S. Energy Consumption, Growth, and Carbon Emission: Challenges Faced by an EU Candidate Member [J]. Ecological Economics, 2009(68): 1667-1675.

3. Trappy and Hsiao, An evaluation model for low carbon island policy: the case of Taiwan's green transportation policy [J]. Energy Policy.2012 (45): 510-515.

4. Kerschner C. Economic de-growth vs. Steady-state economy[J]. Journal of Cleaner Production, 2010(6): 544-551.

5. Daly H E. Beyond growth: the economics of sustainable development [M]. 2006.

6. Common M. Measuring National Economics Performance without Using Prices[J].Ecological Economics, 2007, 64: 92-102. 